\title{
Chronic Hepatitis C in Children in the Russian Federation: A Multicenter Study
}

\author{
Volynets $\mathrm{GV}^{1^{*}}$, Khavkin $\mathrm{AI}^{1}$, Skvortsova $\mathrm{TA}^{2}$, Panfilova $\mathrm{VN}^{3}$, Rogozina $\mathrm{NV}^{4}$ and Komarova $\mathrm{ON}^{1}$ \\ ${ }^{1}$ Pirogov Russian National Research Medical University, Veltischev Research and Clinical Institute of Pediatrics, Russia \\ ${ }^{2}$ State Budgetary Health Care Institution Morozovskaya Children's City Clinical Hospital of the Moscow City Health Department, \\ Russia \\ ${ }^{3}$ Krasnoyarsk State Medical University of the Ministry of Health and Social Development of the Russian Federation, Russia \\ ${ }^{4}$ Pediatric Research and Clinical Center for Infectious Diseases, Saint-Petersburg, Russia
}

*Corresponding author: Volynets GV, MD, PhD, Dr Sci, Chief Researcher, Department of Gastroenterology, Pirogov Russian National Research Medical University, Veltischev Research and Clinical Institute of Pediatrics. Moscow, str. Taldomskaya 2, Russia, 125412, Tel: +7(985)417-51-54, E-mail: volynec_g@mail.ru

Citation: Volynets GV, Khavkin AI, Skvortsova TA, Panfilova VN, Rogozina NV, et al. (2018) Chronic Hepatitis C in Children in the Russian Federation: A Multicenter Study. J Gastroenterol Metabol 1: 102

Article history: Received: 29 January 2018, Accepted: 20 February 2018, Published: 21 February 2018

\begin{abstract}
We present the results of a multicenter epidemiological study of chronic hepatitis $\mathrm{C}$ (CHC) in the children population of Russia, which reflect the data of a study of 306 children with CHC from three regions (Central, North-Western and Siberian Federal Districts) and which was conducted in November 2014 to July 2017. The article shows the evolution of the primary disease in children (aged up to 17 years old) of CHC in Russia for the period of 2006-2016 (first diagnosis per 100,000 population of corresponding age). We showed the ways of infection of children with hepatitis $\mathrm{C}$ virus ( $\mathrm{HCV}$ ), among which the most common is perinatal. We described the frequency of occurrence of different HCV genotypes in children in Russia. Results of expression of liver fibrosis by elastography method are presented; the correlation between duration of infection and severity of liver fibrosis in children was shown. Besides, the results of a morphological study of liver biopsy specimens with $\mathrm{CHC}$ in children, as well as the effectiveness of various schemes of interferon therapy for $\mathrm{CHC}$ in children were presented.
\end{abstract}

Keywords: Chronic Hepatitis C; Morbidity; Children; Liver Fibrosis

List of abbreviations: CHC: chronic hepatitis C; DAAs: Despite new direct-acting antivirals; GT: genotype; HCC: hepatocellular carcinoma; HCV: hepatitis C virus; IFN: interferon; IQR: interquartile range; PegIFN: pegylated interferon; RBV: ribavirin; SVR: sustained virological response; TE: transient elastography.

\section{Introduction}

Primary disease of chronic hepatitis C (CHC) in Russia increased from 12.9/100 000 population in 1999 to $42.6 / 100$ 000 population in 2009, that is more than 3 times. In 2013-2016, it was 32.26-39.94-38.04-36.2 cases per 1,00,000 population, respectively. The proportion of children under the age of 14 in the age structure of all patients with CHC is 0.7 percent in 2008-2013. This once again proves that children are not frequently involved in HCV epidemic [1].

The number of CHC patients registered in Russia is as high as 3.2 million [2]. Many adults die of liver failure or hepatocellular carcinoma (HCC). The most prevalent genotype is $1 \mathrm{~b}$, accounting for $54.8 \%$, the less prevalent is GT3 (35.1\%) and least prevalent is GT2 (8.2\%) [3]. The pediatric HCV infection in Russia is not well described.

Most children infected with HCV have CHC, while 7-20\% of them have spontaneous virus elimination [4-6]. It is established that the progression of liver fibrosis to cirrhosis in children with chronic HCV infection is found with a frequency of about 2-3\% [4]. However, there are reports of cases of liver cirrhosis as a result of HCV infection in children aged 3-4 years, and there have been cases of HCC in adolescence [7]. It is shown that fibrosis in children can progress [8].

Despite new direct-acting antivirals (DAAs) for adults available since 2013, they are not yet licensed for children [9]. The current standard of care for treatment of children with CHC remains PegIFN-based regimens. 


\section{Aim}

Our aim was to provide a detailed characterization of children and adolescents with CHC in 3 paediatric hepatology centres in Russia, with regard to mode of acquisition, HCV genotype, clinical status, type of treatment and treatment outcomes.

\section{Method}

A cross-sectional study of children and adolescents with $\mathrm{CHC}$ observed in three centres (Moscow, Saint-Petersburg and Krasnoyarsk) was conducted in November 2014 to July 2017.

Patients diagnosed at the age of 18 months to 18 years with confirmed HCV acquired perinatally or in childhood, were included.

Anonymised individual patient data were collected according to a standard protocol using online REDCap (Research electronic data capture) tool.

Ethics approval for the study was acquired at the Federal State Autonomous Institution "National Scientific and Practical Center of Children's Health" of the Ministry of Health of the Russian Federation, Moscow.

\section{Definitions}

CHC was defined as detectable HCV RNA in $\geq 2$ blood samples over at least 6 months.

Liver fibrosis stages were evaluated by liver biopsy scoring systems according to Desmet whereas elastography was evaluated according to Metavir [10].

Results of liver stiffness evaluated by transient elastography (TE) were categorised as normal $(<5.8 \mathrm{kPa})$, mild increase $(5.9-\leq 7.2 \mathrm{kPa})$, moderate increase $(7.3-9.5 \mathrm{kPa})$, severe increase $(9.6-<12.5 \mathrm{kPa})$, and possible cirrhosis $(\geq 12.6 \mathrm{kPa})[11,12]$. The most recent TE result per patient reported was used in our present analysis.

Successful outcome was defined as sustained virological response 24 weeks after the end of treatment (SVR24).

The study of the dynamics of HCV morbidity of children population in Russia was based on the official statistical data of Federal state statistics service.

\section{Statistical Analysis}

Descriptive analyses were conducted. Medians were presented with interquartile range (IQR). Univariable comparisons were assessed using the $\mathrm{X}^{2}$ test, $\mathrm{X}^{2}$ test for trend or Fisher's exact test, as appropriate.

\section{Results}

The dynamics of primary disease of children population (first diagnosis per 100,000 population of corresponding age) with CHC in the Russian Federation for the period 2006-2016 is presented in Figure 1. There is a decrease by more than 2.5 times (Figure 1).

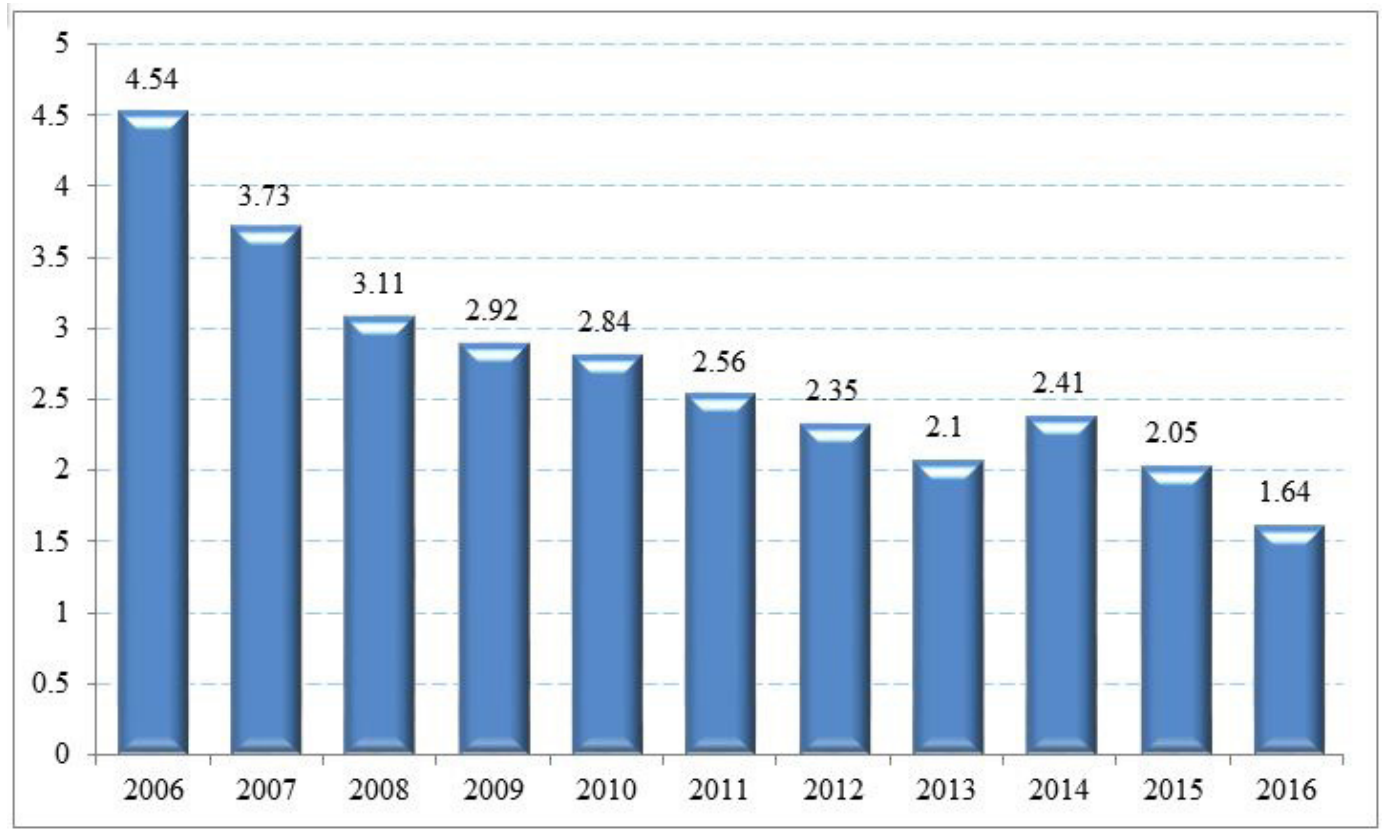

Figure 1: Dynamics of primary disease of children and adolescents (per 100,000 population of corresponding age) patients in Russia 
It is established that the main route of infection for children is perinatal infection (Table 1).

\begin{tabular}{|c|c|c|c|c|}
\hline & & Perinatally Infected & Other & Total \\
\hline \multicolumn{2}{|c|}{ Children under follow-up: n (\%) } & $199(65,0)$ & $107(36)$ & $306(100)$ \\
\hline \multirow{2}{*}{ Sex, n (\%) } & Male & 98 & 60 & $158(52)$ \\
\hline & Female & 101 & 47 & $148(48)$ \\
\hline \multicolumn{2}{|c|}{ Age at enrolment (years): median (IQR) } & $10[7,12]$ & $17[12,21]$ & $10.6[7.2,14.6]$ \\
\hline \multirow{4}{*}{ Age at diagnosis: $\mathbf{n}(\%)$} & $<2$ years & 105 & 3 & $108(35)$ \\
\hline & $2-5$ years & 71 & 22 & $93(30)$ \\
\hline & 6-10 years & 14 & 42 & $56(18)$ \\
\hline & $>10$ year & 9 & 40 & $49(16)$ \\
\hline \multirow{6}{*}{ Reason for HCV test: n (\%) } & Family member HCV+ & 186 & 4 & $190(62)$ \\
\hline & History of transfusion & 1 & 32 & $33(11)$ \\
\hline & History of invasive procedures & 0 & 25 & $25(8)$ \\
\hline & Clinical symptoms & 9 & 20 & $29(9)$ \\
\hline & Elevated transaminases & 36 & 50 & $86(28)$ \\
\hline & Screening prior to operation & 8 & 22 & $30(10)$ \\
\hline \multirow{5}{*}{ HCV genotype: $n(\%)$} & 1a & 8 & 2 & $10(3)$ \\
\hline & $1 b$ & 92 & 67 & $159(52)$ \\
\hline & 2 & 9 & 6 & $15(5)$ \\
\hline & 3 & 81 & 31 & $112(37)$ \\
\hline & Unknown & 9 & 1 & $10(3)$ \\
\hline
\end{tabular}

Table 2 shows 93 (30\%) children with liver biopsy, at the median age of 9 years (at first biopsy), whereas 38 (41\%) had significant fibrosis $(\geq \mathrm{F} 2)$ (Table 2). There was a significant association between older age and significant fibrosis: $15 / 49(30 \%)$ children aged $<10$ had fibrosis $\geq F 2$ compared with $23 / 43(53 \%)$ children aged $\geq 10$ ( $\mathrm{p}=0,03383)$.

\begin{tabular}{|c|c|c|c|c|}
\hline \multicolumn{2}{|c|}{} & Perinatally Infected & Other & Total \\
\hline \multirow{2}{*}{ Children with liver biopsy, n (\%) } & $43(46)$ & $50(55)$ & $93(100)$ \\
\hline \multirow{3}{*}{ Sex, n(\%) } & Male & 21 & 26 & $47(51)$ \\
\cline { 2 - 5 } & Female & 22 & 24 & $46(49)$ \\
\hline \multirow{3}{*}{$\begin{array}{c}\text { Staging of fibrosis: } \\
\text { n (\%) }\end{array}$} & F0 & $4(10)$ & $6(12)$ & $10(11)$ \\
\cline { 2 - 5 } & F1 & $24(59)$ & $20(40)$ & $44(48)$ \\
\cline { 2 - 5 } & F2/3 & $15(35)$ & $23(46)$ & $38(41)$ \\
\hline \multirow{3}{*}{$\begin{array}{c}\text { Necroinflammation / } \\
\text { activity }\end{array}$} & F4 & 0 & $1(2)$ & $1(1)$ \\
\cline { 2 - 5 } & Minimal / no activity & $21(51)$ & $20(40)$ & $41(44)$ \\
\cline { 2 - 5 } & Moderate & $19(45)$ & $25(50)$ & $44(47)$ \\
\cline { 2 - 5 } & Severe & $2(5)$ & $5(10)$ & $7(8)$ \\
\hline
\end{tabular}

Table 2: Results of liver biopsy, by mode of acquisition

205 (67\%) children had at least one TE measurement. Greater liver stiffness was concentrated in patients aged $\geq 15$ years.

The results of elastography patients with perinatally acquired HCV show that there was a significant association between duration of infection and increased liver stiffness (10/115 (8.7\%) of children aged $<10$ had TE $>5.8 \mathrm{kPa}$ compared with 10/109 (9\%) of patients aged $\geq 10(\mathrm{p}=0.02672)$, (Figure $2 \mathrm{a}, 2 \mathrm{~b})$.

A total of 207 (68\%) children received treatment (Table 3). Of those treated, 100 (49\%) children achieved SVR 24. Of those treated with PegIFN/RBV, 66\% achieved SVR24 (63\% with GT1, and 74\% with GT2/3).

\section{Discussion}

The study represents the actual situation of the epidemiology of HCV infection among children population of Russia conducted with a large number of patients in different regions of Russia (Central, Northwestern and Siberian Federal Districts). The results of the multicenter study indicate that the incidence of $\mathrm{HCV}$ in children is not higher than those in other regions of the world. It is 
established that the main route of infection for children is perinatal, which proves results of researchers in other countries $[13,14]$.

\begin{tabular}{|c|c|c|}
\hline \multicolumn{2}{|c|}{ Treated children, $\mathbf{n}$} & 207 \\
\hline \multirow{7}{*}{ Treatment: $\mathbf{n}(\%)$} & PegIFN alfa- $2 b$ and ribavirin & $116(56)$ \\
\hline & IFN alfa-2b plus ribavirin & $12(6)$ \\
\hline & IFN alfa-2a plus ribavirin & $2(1)$ \\
\hline & PegIFN alfa-2b only & $2(1)$ \\
\hline & IFN alfa-2a only & $31(15)$ \\
\hline & IFN alfa-2b only & $28(14)$ \\
\hline & Other & $16(8)$ \\
\hline \multicolumn{2}{|c|}{ Treatment prematurely discontinued: $n(\%)$} & $39(19)$ \\
\hline \multirow{3}{*}{$\begin{array}{l}\text { Reasons for premature } \\
\text { discontinuation: } \mathbf{n}(\%)\end{array}$} & Inadequate response & $29(14)$ \\
\hline & Drug reactions & $6(3)$ \\
\hline & Family decision & $4(2)$ \\
\hline \multirow{8}{*}{ Side effects ${ }^{*}$} & None & $14(7)$ \\
\hline & Flu-like symptoms & $184(91)$ \\
\hline & Local reaction at injection site & $114(56)$ \\
\hline & Neutropenia & $57(28)$ \\
\hline & Anaemia & $46(23)$ \\
\hline & Poor weight gain/weight loss & $40(20)$ \\
\hline & Hair loss & $39(19)$ \\
\hline & Depression/anxiety & $31(15)$ \\
\hline
\end{tabular}

*more than one side effect may be reported in the same child

Table 3: Treatment characteristics and side effects

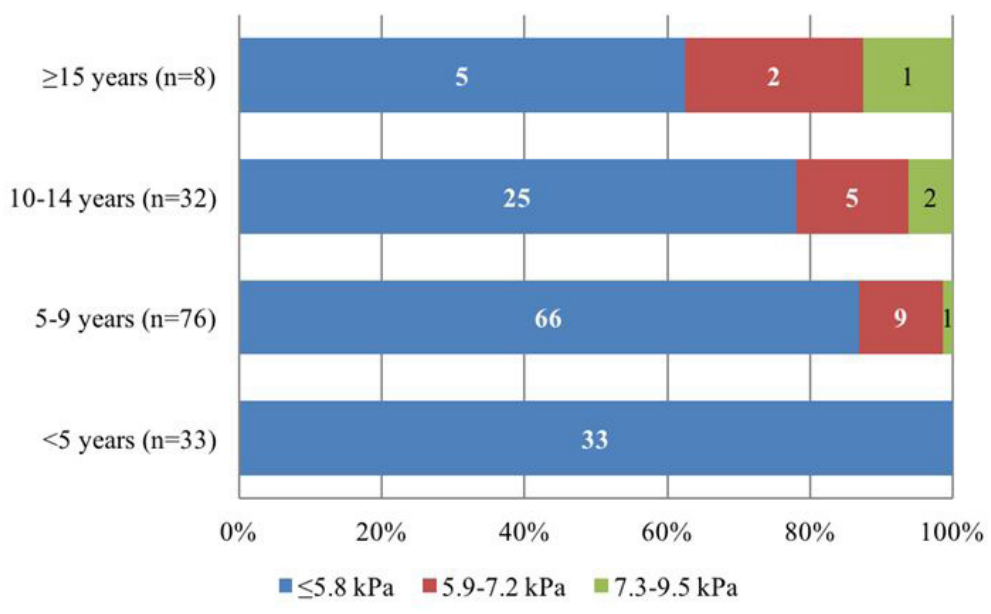

Figure 2a: Results of TE in perinatally acquired HCV, by age at the test $(n=149)$

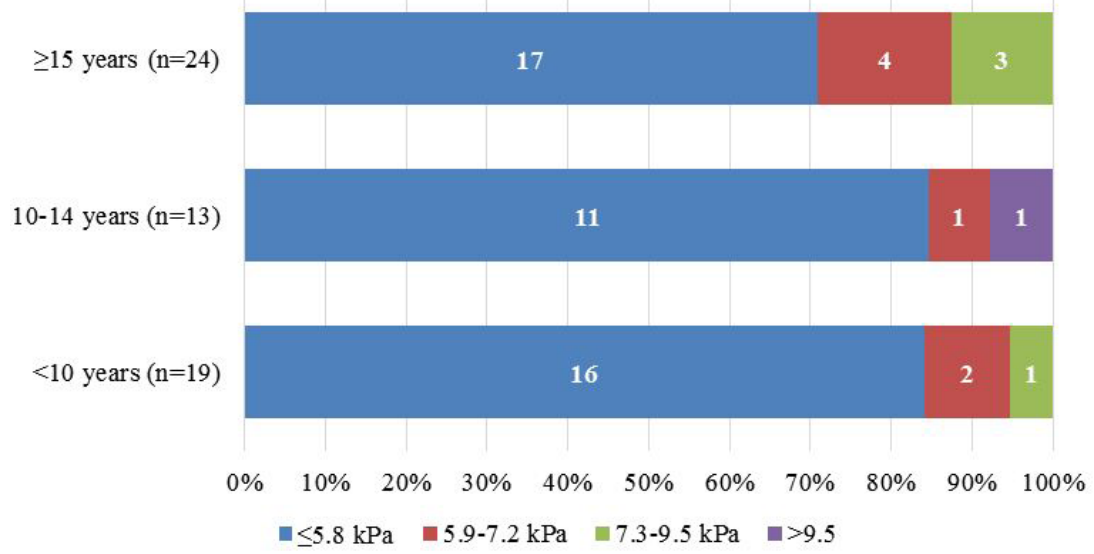

Figure 2b: Results of TE in non-perinatally acquired HCV, by age at the test $(n=56)$ 
It is shown that the unspecified or mixed genotypes of $\mathrm{HCV}$ are $3 \%$ of the number of infections in children. The predominant $\mathrm{HCV}$ genotype is $1 \mathrm{~b}$, while genotype $1 \mathrm{a}$ is much rarer. Genotype $3 \mathrm{HCV}$ is ranked second in frequency of occurrence. Similar to our study, HCV genotypes 1 and 3 are most common throughout the world [15]. Knowing the prevalence of HCV genotypes in different countries is important for understanding the pathogenesis of the disease, identifying approaches to therapy, and developing and testing vaccines against $\mathrm{HCV}$.

\section{Conclusion}

- Distribution of HCV genotypes in children in the study was similar to distribution reported in adults, with GT1b being a predominant genotype (51\%), followed by GT3 (31\%).

- The most frequent reason for HCV testing was HCV infection in a family member (usually the mother), the second most common reason were elevated transaminases.

- Greater liver stiffness evaluated by TE was concentrated in children aged $\geq 15$ years. In children with perinatally acquired HCV, there was a significant association between duration of infection and increased liver stiffness. Over a third of children who had liver biopsy had significant fibrosis $(\geq \mathrm{F} 2)$; this was associated with older age.

- Over two-thirds of children were treated and less than half of them achieved SVR 24. The majority of treated children (93\%) experienced side effects.

- A substantial proportion of older children, adolescents and youth with chronic HCV acquired perinatally or in childhood have progressive liver disease.

- Currently used treatment regimens are prolonged, have suboptimal outcomes and poor safety profile.

- There is an urgent need to speed up the access to new DAAs, particularly for older children and adolescents.

\section{Acknowledgement}

We thank children and their families and clinicians of the Federal State Autonomous Institution "National Medical Research Center of Children's Health" of the Ministry of Health of the Russian Federation who look after them and made this study possible.

The study was funded by PENTA foundation.

\section{References}

1. Mukomolov S, Trifonova G, Levakova I, Bolsun D, Krivanogova E (2016) Hepatitis C in the Russian Federation: challenges and future directions. Hepat Med 8: 51-60.

2. Hope V.D, Eramova I, Capurro D, Donoghoe M. C (2014) Prevalence and estimation of hepatitis B and C infections in the WHO European Region: a review of data focusing on the countries outside the European Union and the European Free Trade Association. Epidemiol Infect 142: 270-86.

3. Gower E, Estes C, Blach S, Razavi-Shearer K, Razavi H (2014) Global epidemiology and genotype distribution of the hepatitis C virus infection. J Hepatol 61: S45-57.

4. Bortolotti F, Verucchi G, Cammà C, Cabibbo G, Zancan L, et al. (2008) Long-term course of chronic hepatitis C in children: from viral clearance to end-stage liver disease. Gastroenterology 134: 1900-7.

5. European Paediatric Hepatitis C Virus Network (2005) Three broad modalities in the natural history of vertically acquired hepatitis C virus infection. Clin Infect Dis $41: 45-51$.

6. Castellino S, Lensing S, Riely C, Rai SN, Davila R, et al. (2004) The epidemiology of chronic hepatitis C infection in survivors of childhood cancer: an update of the St Jude Children's Research Hospital hepatitis C seropositive cohort. Blood 103: 2460-6.

7. González-Peralta RP, Langham MR Jr, Andres JM, Mohan P, Colombani PM, et al. (2009) Hepatocellular carcinoma in 2 young adolescents with chronic hepatitis C. J Pediatr Gastroenterol Nutr 48: 630-5.

8. Mohan P, Barton BA, Narkewicz MR, Molleston JP, Gonzalez-Peralta RP, et al. (2013) Evaluating progression of liver disease from repeat liver biopsies in children with chronic hepatitis C: a retrospective study. Hepatology 58: 1580-6.

9. Thorne C, Indolfi G, Turkova A, Giaquinto C, Nastouli E (2015) Treating hepatitis C virus in children: time for a new paradigm. J Virus Erad 1: 203-5.

10. Shiha G, Zalata K (2011) Ishak versus METAVIR: terminology, convertibility and correlation with laboratory changes in chronic hepatitis C. In: Liver Biopsy, Takahashi H (edn). InTech.

11. Nobili V, Vizzutti F, Arena U, Abraldes J.G, Marra F, et al. (2008) Accuracy and reproducibility of transient elastography for the diagnosis of fibrosis in pediatric nonalcoholic steatohepatitis. Hepatology. 48: 442-8.

12. Castéra L, Vergniol J, Foucher J, Le Bail B, Chanteloup E, et al. (2005) Prospective comparison of transient elastography, Fibrotest, APRI, and liver biopsy for the assessment of fibrosis in chronic hepatitis C. Gastroenterology 128: 343-50.

13. Mast E.E, Hwang L.Y, Seto D.S, Nolte F.S, Nainan O.V, et al. (2005) Risk factors for perinatal transmission of hepatitis C virus and the natural history of HCV infection acquired in infancy. J. Infect Dis 192: 1880-9.

14. Benova L, Mohamoud YA, Calvert C, Abu-Raddad LJ (2014) Vertical transmission of hepatitis C virus: systematic review and meta-analysis. Clin Infect Dis. 2014 59: 765-73.

15. Petruzziello A, Marigliano S, Loquercio G, Cozzolino A, Cacciapuoti C (2016) Global epidemiology of hepatitis C virus infection: An up-date of the distribution and circulation of hepatitis $\mathrm{C}$ virus genotypes. World J Gastroenterol 22: 7824-40. 